\title{
Teaching Microbiology through Application Based Learning
}

\author{
Nagdeo, N., Bhakre, U., Kawthalkar, A., Manohar, T.
}

\begin{abstract}
Microbiology is usually taught in classroom with little exposure to practical's and clinical aspects. This makes the subject clinically irrelevant as students fail to understand the utility of the subject.

Study was conducted in Department of Microbiology by applying a new teaching- learning method to know about practical application of hospital waste management through project work. Total of 95 students participated in this study. The whole batch was divided into small batches. Pre Test and Post Test Questionnaires were given to the whole batch. Conventional lecture was delivered to 72 students and the other students were subjected to hospital project work. This hospital project work involved active learning by the students.
\end{abstract}

According to students, this method has many advantages. The visual impression leads to better understanding of the subject. There is active involvement of students leading to self-learning. As it is a focused learning, retention of knowledge is for a longer time. Hospital project work makes learning interesting and effective. There is ease of understanding as doubts are cleared by direct observation.

All faculty members felt that this method will help in better understanding of the subject. Everybody felt that this method is feasible in undergraduate teaching with some efforts. Only hindrance may be lack of time, and lack of manpower. However there are many advantages such as students learning better with practical demonstration, learning with interest thus this method stimulates self-learning.

\section{Introduction}

In conventional teaching all subjects are usually taught without having any coordination with each other. It involves didactic lectures which are a mere passage of information from teacher to the student with no participation from the students. In view of the dissatisfaction about the conventional type of teaching, curricula and methods, various new ways have been suggested like Problem Based Learning (PBL), Integrated teaching, Microteaching, Objective Structured Practical Examination (OSPE) and Objective Structured Clinical Examination (OSCE) (Bapat, 2009).

It is well known fact that learning environment has a direct influence on attainment and retention of knowledge.

NKP Salve Institute of Medival Sciences \&Research Centre, Nagpur, India.

Corresponding Author:

Dr. Neena Nagdeo

Associate Professor, Department of Microbiology

NKP Salve Institute of Medival Sciences \& Research Centre, Nagpur, India.

Email: neenagdeo@yahoo.co.in nagdeo_ngp@rediffmail.com
Use of innovative techniques in teaching has certain advantages which include increasing teacher and learner enthusiasm and improving participation of the students.

The traditional passive view of learning involves situations where material is delivered to students using a lecture based format. In contrast, a more modern view of learning is constructivism, where students are expected to be active in the learning process by participating in discussions and collaborative activities (Carpenter, 2006). Active learning is "anything that involves students in doing things and thinking about the things they are doing" (Yoder \& Hochevar, 2005).

In the undergraduate curriculum, Microbiology is usually taught in classroom with little exposure to the practical and clinical aspects. This makes the subject dry and clinically irrelevant as students fail to understand the utility of the subject in practice.

With this view in mind, a study was conducted in Department of Microbiology by applying a new teaching -learning method to understand 
the practical application of hospital waste management through project work.

\section{Aims \& Objectives}

1) To introduce the concept of new teachinglearning method i.e. Application based learning.

2) To know the effectiveness of new technique in learning process.

\section{Methodology}

The study was conducted in Department of Microbiology for II MBBS first term students. Permission from Ethics Committee of NKPSIMS was taken. A batch of 95 students was included in this study. Pre-test questionnaire was given to the whole batch to know about the prior knowledge of the subject. Then the batch was divided into two small batches $A B$ and $C D$ (figure 1). From the flow chart, it is evident that batches $A$ and $C$ were given only a conventional lecture, batch $B$ was subjected only to a hospital project work and batch $\mathrm{D}$ was subjected to both conventional lecture and hospital project work. Total of 72 students from batch $A, C$ and $D$ attended the lecture. After the lecture post-test questionnaire was given to batch $A$ and $C$ to check the gaining of knowledge, while batch $D$ was sent for the hospital project.
Batch $B$ and batch $D$ were subjected to hospital project work for which 49 students participated. They were asked to visit Medicine and Gynaecology wards, and they interviewed the faculty as well as nursing staff in the ward to collect information regarding hospital waste management. The students also observed the process of waste collection, segregation and disposal in the wards.

A post-test questionnaire was given at the end of the visit to check the gaining of knowledge. This project was carried out during the hours which are allotted for Microbiology practicals. Feedback was collected by Questionnaire:

1) From 49 students to know the effectiveness of this new teaching -learning method

2) From 18 teaching and non-teaching staff to know about the involvement of the students.

\section{Outcome of the Study}

\section{Acquisition of knowledge}

Total of 95 students participated in this project. A standard questionnaire was given to them.

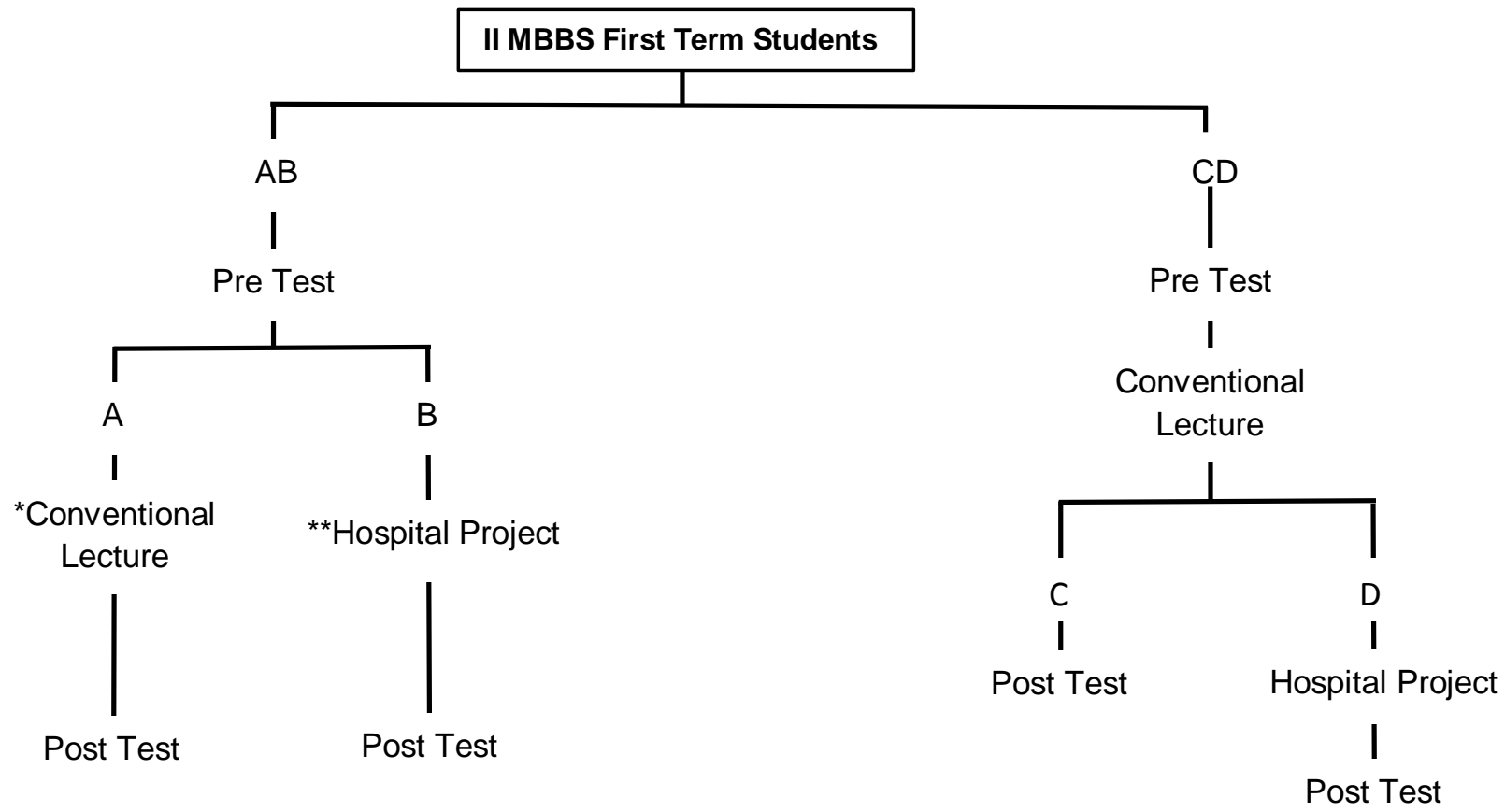

Figure 1: Batch Division Flow Chart

* Conventional lecture on Hospital Waste Management

**Hospital Project: visit to Medicine and Gynaecology wards where students interviewed the teaching and non-teaching staff to gain the knowledge regarding the hospital waste management. They observed the actual utility of this topic in practice. 
Considering the pre-test questionnaire and post-test questionnaire, there was a definite improvement in knowledge. When results of the post-test in all the groups were compared, it was found that all the students benefitted. Batch which was received the conventional lecture and the other batch which was subjected to hospital project, both acquired knowledge equally. There was no difference in immediate acquisition of knowledge in all the groups irrespective of the method of teaching (Tables 1 \& 2).

Table 1: Batch undergoing conventional lecture $(n=72)$

\begin{tabular}{ccc}
\hline Q.No. & $\begin{array}{c}\text { Pre Test } \\
\text { Correct answer }(\%)\end{array}$ & $\begin{array}{c}\text { Post Test } \\
\text { Correct answer }(\%)\end{array}$ \\
\hline 1 & 54.16 & 95.83 \\
2 & 50.00 & 94.44 \\
3 & 43.05 & 88.88 \\
4 & 50.00 & 88.88 \\
5 & 48.61 & 95.83 \\
6 & 47.22 & 94.44 \\
7 & 50.00 & 94.44 \\
8 & 47.22 & 95.83 \\
9 & 47.22 & 98.61 \\
10 & 45.83 & 93.05 \\
11 & 45.83 & 94.44 \\
12 & 52.77 & 94.44 \\
13 & 41.66 & 93.05 \\
14 & 52.77 & 90.27 \\
15 & 43.05 & 94.44 \\
16 & 27.77 & 97.22 \\
17 & 34.72 & 97.22 \\
\hline
\end{tabular}

\section{Students' perception about application based learning}

49 students were subjected to the hospital project .Feedback questionnaire was given to them. As evident from Figure 2, all the students agreed that this method will help in theory examination as well as in clinical practice. A majority of students 34 (69\%) felt that the number of students in the class should be less than 30 . While 10 students recommended that 30-50 students can be accommodated in the class and only 5 students agreed for 50-70 students in a class. This indicates inclination of students for a small group teaching.

Table 2: Batch undergoing Hospital Project (n=49)

\begin{tabular}{ccc}
\hline Q.No & $\begin{array}{c}\text { Pre Test Correct } \\
\text { answer(\%) }\end{array}$ & $\begin{array}{c}\text { Post Test Correct } \\
\text { answer(\%) }\end{array}$ \\
\hline 1 & 51.02 & 95.91 \\
2 & 51.02 & 93.87 \\
3 & 51.02 & 93.87 \\
4 & 59.18 & 89.79 \\
5 & 57.14 & 93.87 \\
6 & 55.10 & 87.75 \\
7 & 48.97 & 87.75 \\
8 & 46.93 & 91.83 \\
9 & 46.93 & 89.79 \\
10 & 48.97 & 91.83 \\
11 & 51.02 & 89.79 \\
12 & 48.97 & 85.71 \\
13 & 48.97 & 87.75 \\
14 & 51.02 & 91.83 \\
15 & 48.97 & 93.87 \\
16 & 40.81 & 97.95 \\
17 & 51.02 & 97.95 \\
\hline
\end{tabular}




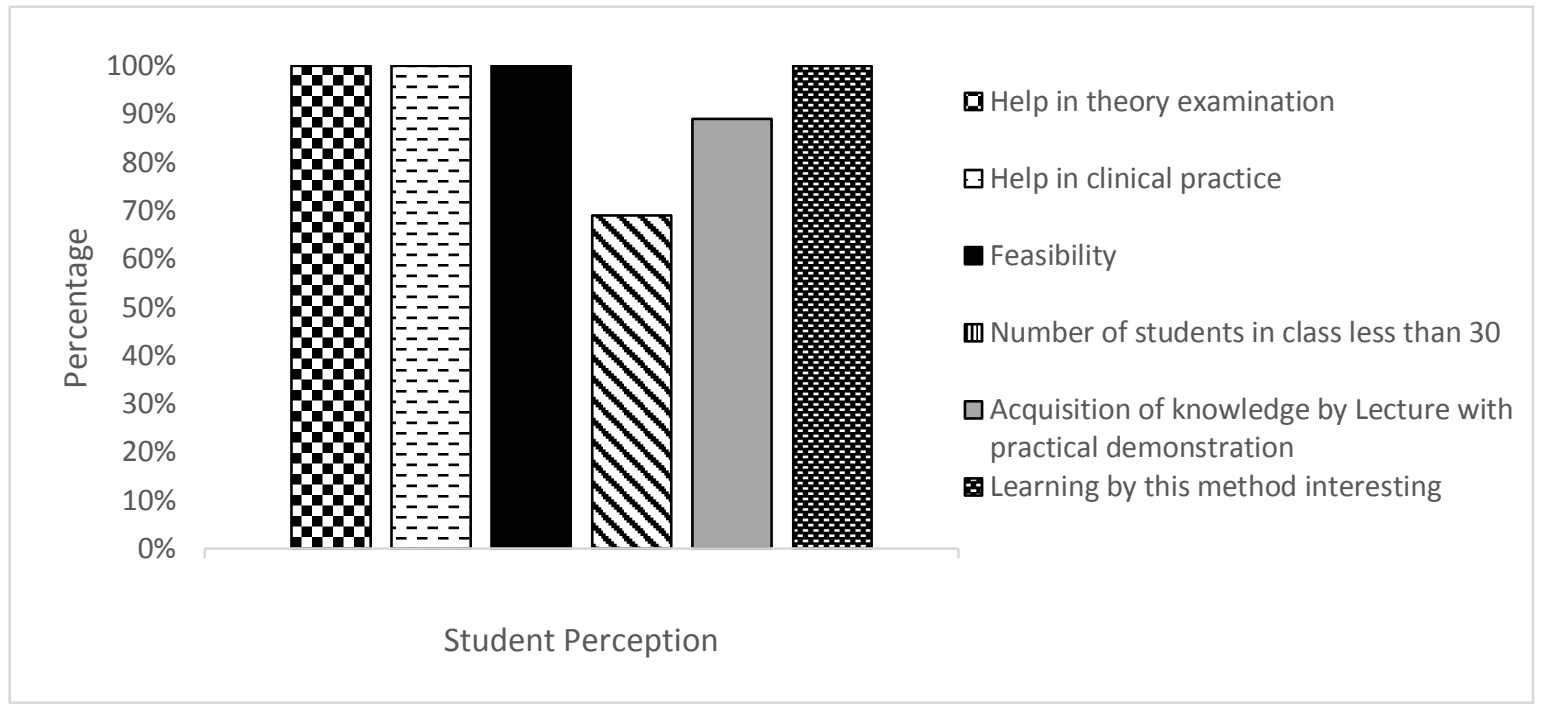

Figure 2: Students' perception about application based learning

When asked about the acquisition of knowledge, $89 \%$ believed that lecture with practical application is the best. Only one student opted for conventional lecture and only two students for practical demonstration. This indicates importance of practical application of knowledge when learning any topic. In a way, students are suggesting that conventional lecture should be followed by practical application of the subject.

Everybody felt that teaching microbiology through application based learning was interesting. Students even suggested some topics which can be covered by this method. The topics include sterilization and disinfection, collection and transport of specimens. $100 \%$ of the students agreed that this method is feasible in II MBBS teaching.

\section{Faculty Feedback}

The teaching and non-teaching staff in Gynecology Department and Medicine Department guided the students. They observed that during ward visit all the students were enthusiastic. $88 \%$ students asked the relevant questions. (Figure 3) 18 faculty members participated in this study. All felt that this method will definitely help in better understanding of the subject or topic. Everybody felt that this method is feasible in undergraduate teaching with some efforts. Only hindrance may be lack of time and lack of manpower to implement this method routinely. However there are many advantages such as students learning better with practical demonstration, they learning with interest thus this method stimulates self-learning.

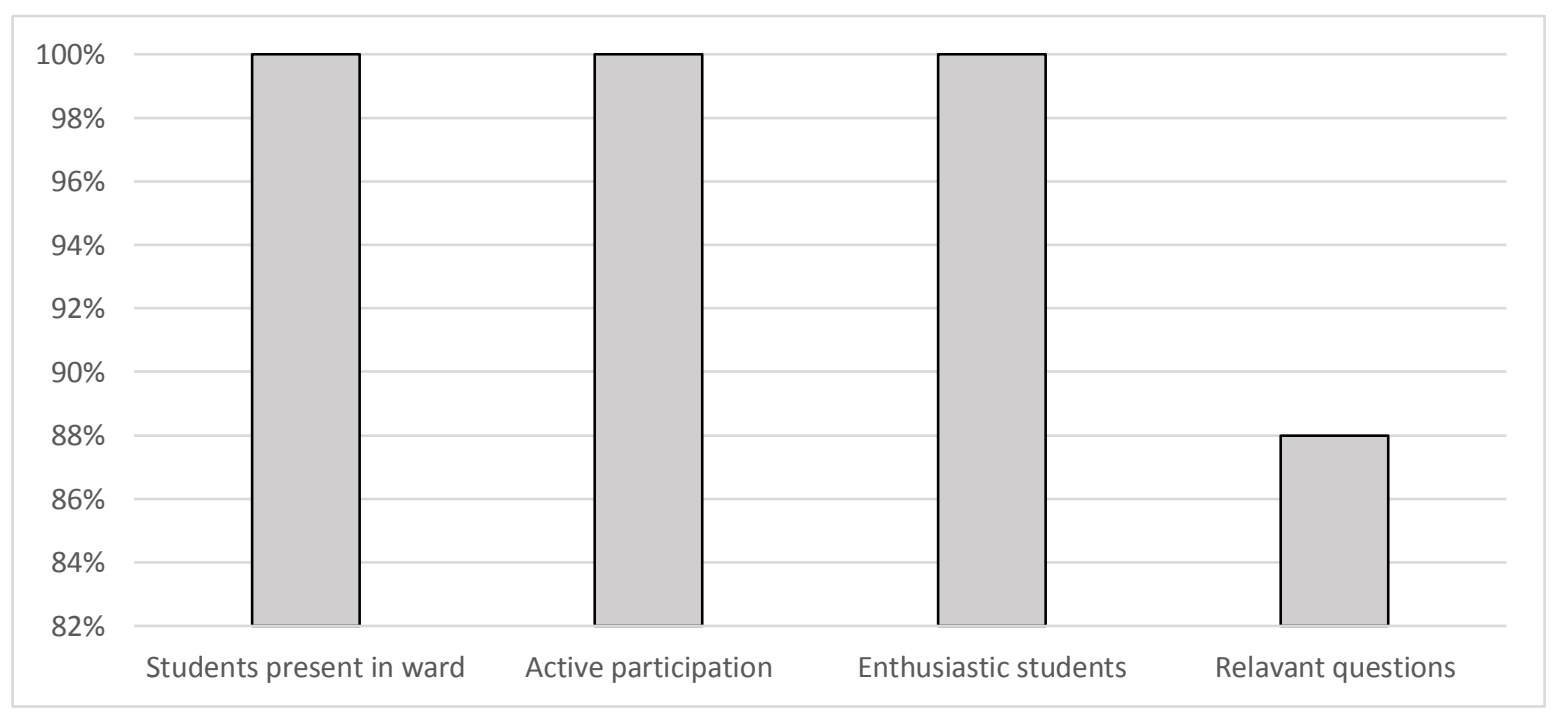

Figure 3: Faculty Feedback 


\section{Discussion}

According to students, this method has many advantages. The visual impression leads to better understanding of the subject, and there is active involvement of the students leading to self-learning. As it is a focused learning, retention of knowledge is for a longer time. Hospital project work makes learning interesting and effective. There is ease of understanding as doubts are cleared by direct observation.

Modern teaching trends in medical education exhibit a paradigm shift from a conventional classroom teaching methods adopted in the past. Non-conventional teaching aids so as to encourage interactive forms of learning in medical students through active participation and integrative reasoning where the relationship of the teacher and the student has undergone tremendous transformation. It is well known that students learn more when they are involved actively in learning than when they are passive recipients of instructions (Nageswari et al. 2004).

According to students, following are the advantages of this new teaching -learning method:

- Students learn better with practical demonstration

- They learn with interest and this method stimulates self-learning.

When asked about the disadvantages of this method, $83 \%$ students believed that there are no disadvantages. While few believed that this method is time consuming, requires more teaching staff, the batches should be divided into small groups otherwise there will be no control over the students, and there should be proper planning for this method. The students felt that if the number of students are more, then the batch will have to be divided into smaller groups which will take more practical hours and the number of faculty staff required will also be more.

Use of innovative techniques requires time, planning and commitment for the teaching process and a belief that the resulting learning will be both more enjoyable and productive. (Handfield-Jones et al. 1993).

\section{Conclusion}

This study revealed that students have improved cognitive domains by this new teaching- learning methodology. The students were enthusiastic towards the new teachinglearning method and benefitted by practical demonstration. The whole faculty showed enthusiasm towards this new approach but was in the opinion that this method could be applicable only to certain selected topics. The teachers agreed that immediate feedback can be taken from the students regarding acquisition of knowledge.

Findings of the this study suggest that faculties teaching large classes should attempt to include constructive, active teaching methods in their courses whenever possible and these methods should be introduced in undergraduate curriculum.

Introduction of this method only to one batch will not be a full proof of effectiveness of new teaching- learning method. Effectiveness can be judged by involving more batches of undergraduate students. But here an attempt has been taken to introduce this method to the undergraduate students so that teaching learning is made interesting.

\section{References}

Bapat, S.K. (2009) Modern trends in medical education: A critical appraisal, Kathmandu University Medical Journal, 7, 3, pp. 330-333.

Carpenter, J.M. (2006) Effective teaching methods for large classes, Journal of Family \& Consumer Sciences Education, 24, 2, pp. 13-23.

Handfield-Jones R., Nasmith, L., Steinert, Y. \& Lawn, N. (1993) Creativity in medical education: the use of innovative techniques in clinical teaching, Medical Teacher, 15, 1, pp.3-10.

Nageswari, K.S., Malhotra, A.S., Kapoor, N. \& Kaur, G. (2004) Pedagogical effectiveness of innovative teaching methods initiated at the Department of Physiology, Government Medical College, Chandigarh, Advances in Physiology Education, 28, 2, pp. 51-58.

Simkins, S. \& Allen, S. (2000) Pretesting students to improve teaching and learning, International Advances in Economic Research, 6, 1, pp. 100-112.

Yoder, J.D. \& Hochevar, C.M. (2005) Encouraging active learning can improve students'performance on examinations, Teaching of Psychology, 32, 2, pp. 91-95. 